\title{
Brueghel's syndrome, report of a case with postmortem studies
}

\author{
E GARCÍA-ALBEA, O FRANCH, D MUÑOZ AND J R RICOY \\ From the Ciudad Sanitaria de la Seguridad Sociol " $1^{\circ}$ de Octubre", Servicio de Neurología y Sección de \\ Neuropatología, Madrid.
}

SUMMARY A patient with Brueghel's syndrome is described, who died following a seven year history of oromandibular dystonia with blepharospasm. Postmortem examination of the central nervous system revealed no abnormalities.

Marsden ${ }^{1}$ coined the term "Brueghel's syndrome" as an eponym for idiopathic blepharospasm and/or oromandibular dystonia of adult onset. Oromandibular dystonia is a rare and extremely disabling entity. Meige ${ }^{2}$ described the first patient and four additional cases ${ }^{3} 4$ had been published before the extensive review of 26 cases by Marsden ${ }^{1}$. Since then a further five cases have been added to the literature ${ }^{5} 6$ This syndrome has been considered as an idiopathic variant of adult onset torsion dystonia ${ }^{1}$. Recently Tolosa and $\mathrm{Lai}^{6}$, who used the term "Meige's disease" have suggested striatal dopaminergic preponderance as being the pathogenesis of the disease.

We were able to carry out a post-mortem examination and neuropathological studies in a case of Brueghel's syndrome.

\section{Case report}

A 62-year-old woman presented seven years before admission with neck pain, interpreted as due to her work as a seamstress. There was no other neurological disease in the family, nor a history of systemic disease, drug use or contact with toxic substances. One year later she began to suffer from jaw spasms triggered by chewing, with simultaneous blepharospasm. A psychiatric examination revealed no abnormalities. She was treated with haloperidol, diazepam and amantadine without benefit. One year before admission severe spasms were almost continuous, the patient remaining with an open mouth, contracted orbicular muscles and right torticollis. On

Address for reprint requests: Dr E Garcia-Albea, Servicio de Neurología, Ciudad Sanitaria de la Seguridad Social "1" de Octubre", Madrid, Spain.

Accepted 13 January 1981 admission to our department a nasogastric tube was inserted to allow feeding. Respiratory spasms with retention of secretions were observed. Mental examination was limited by her communications problems, but showed no abnormality. Dystonic postures or movements were not found in the limbs. The spasms disappeared when sleeping. Haloperidol and benzodiazepines were tried up to toxic doses without any effect on her symptoms. She developed pneumonia and finally died.

Postmortem examination. No relevant findings were present in the extraneural tissues except for bilateral pneumonia. The brain weighed $1260 \mathrm{~g}$; there was minimal arteriosclerosis in the vessels of the circle of Willis. External examination did not show any abnormalities, the dimensions of the gyri and the depth of the sulci being normal. A slight dilation of the third ventricle was the only abnormal feature seen in the macroscopic sections (fig 1); the morphology of the basal ganglia was normal.

Sections of the spinal cord, brain stem, cerebellum and cerebrum were examined microscopically, the sections being embedded in paraffin and stained with haematoxylin and eosin, Nissl, and myelin stain using Spielmeyer's method. Frozen sections of the basal ganglia and midbrain were stained using the following methods: Nissl, Spielmeyer, haematoxylin and eosin, Holzer, PAS, Oil-red-O, Cajal's, Gold sublimate, Hortega silver impregnations and Bielchowsky stain. Small deposits of lipofucsin were seen in the neuronal cytoplasm throughout the system. In the cerebral cortex, neither focal nor diffuse neuronal loss, nor other significant changes were found. The white matter of the cerebral hemispheres, cerebellum and brainstem was well myelinated. The number of cells in the nuclei of the brainstem and spinal cord was normal. The cerebellar cortex was differentiated in three layers; only occasional slight loss of the Purkinje neurones was seen, the deep nuclei being preserved. In the 

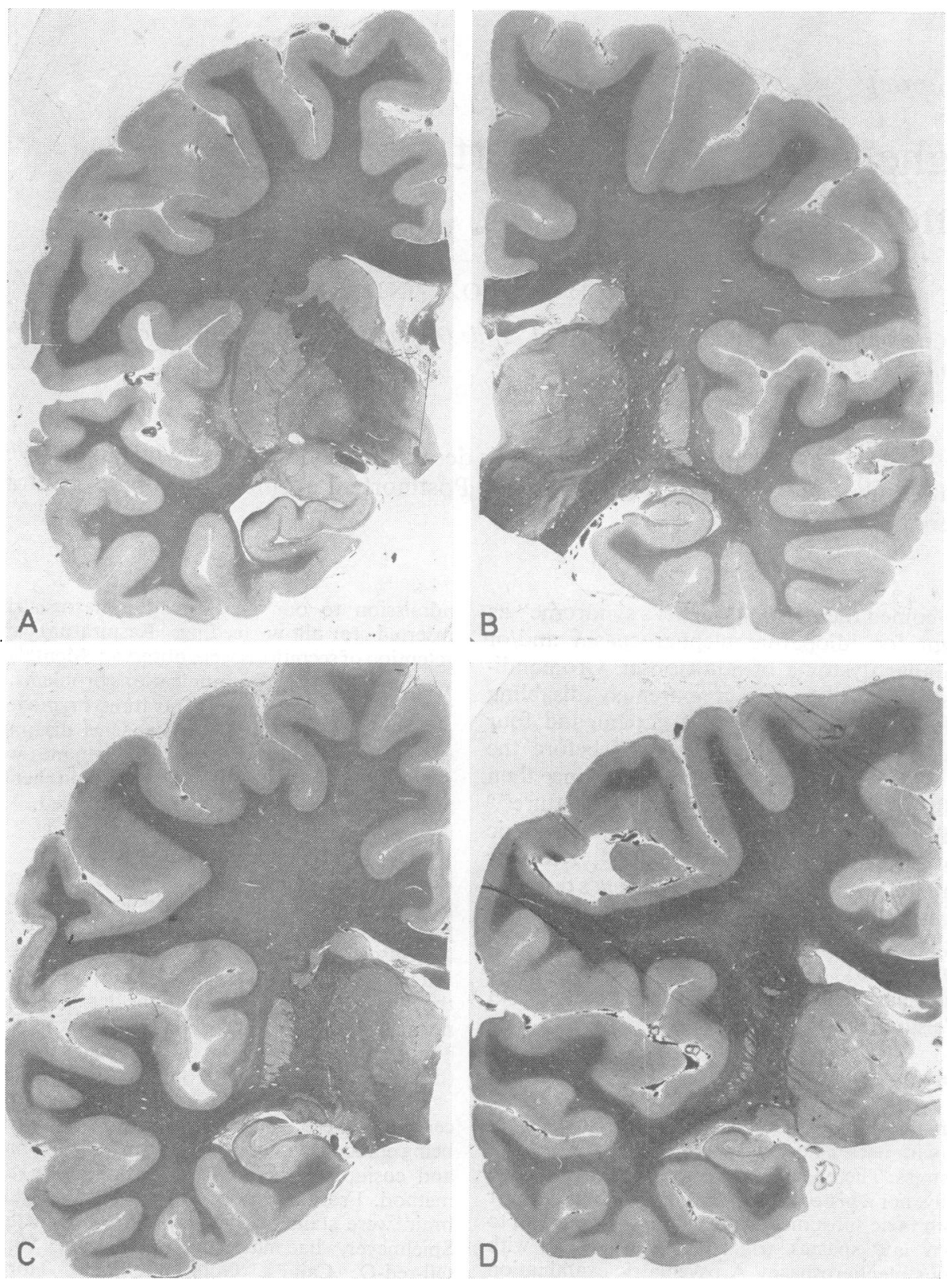

Fig 1 Coronal sections of the hemispheres embedded in celoidine and stained by Spielmeyer's method for myelin. A level of maximal development of lentiform nucleus, $B$ level of red nucleus, $C$ level of lateral geniculate body and centro-medial nucleus of the thalamus, $D$ level of lateral geniculate body. All the anatomical structures in these sections are normal.

basal ganglia, the myelin bundles looked normal. The neuronal content of the nuclei was normal (fig 2). The proportion of neurones in the striatum was carefully assessed, no significant numerical difference being found between those of the patient and six control cases of the same age. No abnormal cells or deposits were found. The postmortem examination of the central nervous system was considered to be normal for the age of the patient. 

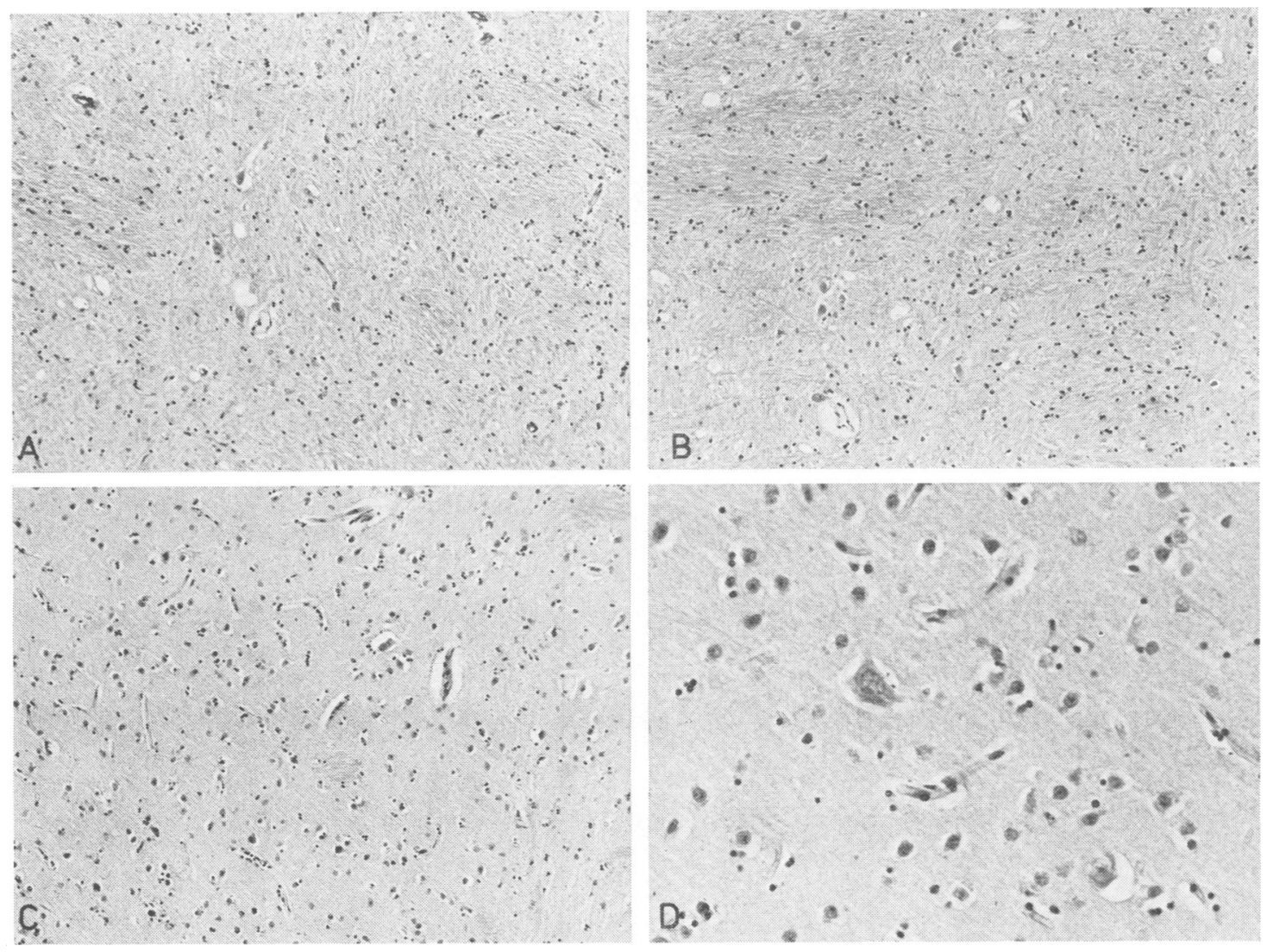

Fig 2 Normal cytological appearance of the lentiform nucleus. $A$ and B: globus pallidus, $C$ and D. putamen. Nissl's method A, B and C $\times 160 ; D \times 320$.

\section{Discussion}

Our patient represented a severe case of Brueghel's syndrome; postmortem examination however was normal. No previous reports of the pathology of this relatively serious disease have been published. It is reasonable to suppose that oromandibular dystonia is the result of some type of changes in the basal ganglia, such dystonic spasms being a known symptom of various well-defined diseases of the basal ganglia such as Wilson's disease and kernicterus, and secondary to intoxication by neuroleptics. The normal necropsy findings are comparable to the lack of pathologic findings in torsion dystonia, ${ }^{7}$ indicating that the mechanism of the disease should be searched for at molecular level; it may be a disorder in catecholamine metabolism as proposed by Wooten et $a l^{8}$ or a dysfunction of the basal ganglia characterised by a state of striatal dopamine preponderance, as suggested by Tolosa and Lai. ${ }^{6}$

\section{References}

1 Marsden, CD. Blepharospasm-oromandibular dystonia syndrome (Brueghel's syndrome). J Neurol Neurosurg Psychiatry 1976; 39:1204-1209.

2 Meige, $\mathrm{H}$. Les convulsions de la face, une forme clinique de convulsion facial, bilatérale et mediane. Revue Neurologique 1910; 20:437-443.

3 Altrocchi, PH. Spontaneous orofacial dyskinesia. Archives of Neurology (Chic) 1972; 26:506-512.

4 Paulson, GW. Meige's syndrome. Dyskinesia of the eyelids and facial muscles. Geriatrics 1972; $27: 69-73$.

5 García-Albea E, Muñoz D, Martínez P, and Goizueta G. Sindrome de Brueghel. Aportación de un caso. 
Revista Clinica Española 1979; 153:69-70.

6 Tolosa ES, Lai C. Meige disease: Striatal dopaminergic preponderance. Neurology (Minneap) 1979; 29:1126-1130.

7 Zeeman W. Pathology of the torsion dystonias (dystonia musculorum deformans). Neurology
(Minneap) 1970; 20:79-88.

8 Wooten F, Eldridge R, Axelrod J, Stern RS. Elevated plasma dopamine-beta-hidroxylase activity in autosomal dominant torsion dystonia. New England Journal of Medicine 1973; 288:284-287. 